Vol. 2, No. 1, Mei 2021, pp 1-6

Https://doi.org/10.36590/kepo.v2i1.136

Http:ojs.yapenas 21 maros.ac.id/index.php/kepo

kepo@yapenas21maros.ac.id

Penerbit: LPPM Akademi Keperawatan Yapenas 21 Maros

\title{
Active Cycle Breathing Technique Terhadap Fungsional Paru Pasien Post CABG (Laporan Kasus Berbasis Bukti)
}

Active Cycle Breathing Technique Exercise on Functional Lung Enhancement on Post Cabg Patient (Evidence Based Case Report)

Riza Pahlawi ${ }^{* 1}$, Zahra Sativani ${ }^{2}$

${ }^{1}$ Program Studi Fisioterapi, Program Pendidikan Vokasi, Universitas Indonesia

${ }^{2}$ Program Studi D4 Fisioterapi, Jurusan Fisioterapi, Poltekkes Kemenkes Jakarta III

Artikel info

Artikel history:

Received: 09-05-2021

Revised : 25-05-2021

Accepted: 26-05-2021

\begin{abstract}
Coronary Artery Bypass Graft (CABG) is an operative action in cases of coronary heart disease (CHD) by cutting and replacing clogged coronary arteries from healthy vessels taken from the legs, arms, or chest. The main clinical problem that arises in post-CABG patients is decreased lung functional capacity, this is due to shortness of breath, pain, decreased thoracic expansion, sputum retention, and decreased pulmonary ventilation. Active Cycle of Breathing Technique (ACBT) is a physiotherapy modality that can be applied in cardiovascular cases. ACBT is a series of exercises that include breathing exercises, coughing exercises, and exercises to expand the chest. To determine the effectiveness of ACBT in increasing lung functional capacity in Post CABG patients, an electronic database search was performed, namely Pubmed, Cochrane, and Google Schoolar. From the search results, 6 articles were selected that met the criteria, namely 1 article on Pubmed and 5 articles on Google scholar. Based on the results of the research that has been presented, it can be concluded that ACBT can increase the functional capacity of the lungs in post $C A B G$ patients as evidenced by the evaluation of the results of the 6 minutes walking test, borg scale, and breath holding time.
\end{abstract}

\section{Abstrak}

Coronary Artery Bypass Graft (CABG) merupakan tindakan operatif pada kasus Penyakit Jantung Koroner (PJK) dengan cara memotong dan mengganti arteri koroner yang tersumbat dari pembuluh sehat yang diambil dari kaki, lengan, atau dada. Masalah klinis utama yang timbul pada pasien post CABG adalah penurunan kemampuan fungsional paru, hal ini disebabkan karena adanya sesak nafas, nyeri, penurunan ekspansi thoraks, retensi sputum, dan penurunan ventilasi paru. Active Cycle of Breathing Technique (ACBT) menjadi salah satu modalitas fisioterapi dalam yang dapat diterapkan pada kasuskasus kardiovaskular. ACBT merupakan serangkaian latihan yang didalamnya terdapat latihan pernapasa, latihan batuk, dan latihan untuk mengembangkan dada. Untuk mengetahui efektivitas ACBT terhadap peningkatan kapasitas fungsional paru pada pasien Post CABG maka dilakukan penelusuran pustaka database elektronik, yaitu Pubmed, Cochrane, dan Google Schoolar. Dari hasil penelusuran diperoleh 6 artikel terpilih yang memenuhi kriteria yaitu 1 artikel pada Pubmed, dan 5 artikel pada Google scholar. Berdasarkan hasil penelitian yang telah dipaparkan dapat disimpulkan bahwa ACBT dapat meningkatkan kapasitas fungsional paru pada 
pasien post CABG dibuktikan dengan evaluasi dari hasil pemeriksaan 6 minutes walking test, borg scale, dan breath holding time.

\begin{tabular}{l}
\hline Kata Kunci: \\
$A C B T ;$ \\
$C A B G$ \\
$P J K$
\end{tabular}

Korespondensi:

Risa Pahlawi, email: rizapahlawi09@gmail.com

\section{PENDAHULUAN}

Menjelankan pola kehidupan yang baik, aktif dalam menjalani kehidupan sehari-hari seperti berolahraga secara teratur, tidak banyak bekerja dalam posisi duduk yang lama, serta dibarengi dengan pola makan yang baik tentu akan menjadikan tubuh kita dalam kondisi yang baik, namun kegagalan dalam mempertahankan kedua hal tersebut dapat mengakibatkan perubahan buruk pada tubuh, salah satunya adalah munculnya gangguan kardiovaskuler. Menurut WHO, cardiovascular disease (CVD) meningkat secara radikal, dengan perkiraan 12 juta orang meninggal setiap tahunnya, kebanyakan di negara berkembang. Sebagai beban pertumbuhan CVD, penyakit jantung koroner (PJK) menjadi penyebab utama dilakukannya operasi jantung di seluruh dunia. PJK mempengaruhi arteri koroner, yang memasok darah beroksigen ke otot jantung. PJK menyebabkan timbulnya plak aterosklerotik di dalam arteri koroner, sehingga terjadilah stenosis arteri. Stenosis dan penurunan suplai darah melalui salah satu segmen arteri ini mungkin memiliki efek berbahaya pada otot jantung dan menyebabkan infark miocard (MI) (Themistocleous et al, 2017; Thomas et al, 2018).

Salah satu penanganan yang dapat dilakukan untuk memperbaiki keadaan arteri pada penyakit jantung koroner ini adalah dengan dilakukannya Coronary Artery Bypass Graft $(\mathrm{CABG})$. $\mathrm{CABG}$ adalah operasi yang digunakan untuk memperbaiki arteri yang tersumbat dan menyempit dengan memotong dan mengganti arteri yang tersumbat tersebut dari pembuluh sehat yang disebut "graft" yang diambil dari kaki, lengan, atau dada (Jain and Mistry, 2017). Namun terdapat beberapa komplikasi yang timbul setelah dilakukannya CABG seperti komplikasi pulmoner. Komplikasi pulmoner yang dimaksud dapat berupa cedera paru, atelektasis, efusi pleura, pneumonia, pneumothoraks, kelainan pertukaran gas, dan pada akhirnya akan berdampak pada penurunan kemampuan fungsional paru (Çirak et al, 2015; Manapunsopee et al, 2020).

Penurunan kemampuan fungsional paru akan diikuti dengan menurunnya nilai dari maximal inspiratory preasure (MIP) dan maximal expiratory preasure (MEP), kedua nilai ini mengindikasikan terjadi penuruanan pada kekuatan otot pernapasan secara signifikan setelah prosedur $\mathrm{CABG}$, sehingga dapat meningkatkan angka mortalitas dan lama masa rawat di rumah sakit. Nilai dari kekuatan otot inspirasi menjadi sebuah indikator yang dapat menggambarkan kemampuan fungsional paru. Kelemahan kekuatan otot inspirasi tentunya akan berdampak pada level kemandirian. Pasien akan cepet merasakan lelah, sesak, aktivitas berkurang, serta dapat menyebabkan retensi sputum (Stein et al, 2009; Manapunsopee et al, 2020).

Untuk mencegah dan mengontrol komplikasi paru tersebut dilakukanlah penanganan fisioterapi berupa latihan yang bertujuan untuk meningatkan kekuatan otot inspirasi dengan chest physiotherapy. Salah satu metode chest physiotherapy yang dapat digunakan yaitu Active Cycle of Breathing Technique (ACBT). ACBT adalah teknik pernapasan aktif yang dilakukan oleh pasien untuk membantu pengeluaran sekresi pada bronkus. Siklus umum ACBT melibatkan kontrol pernapasan, pelatihan ekspansi, dan teknik huffing. Jumlah dan frekuensi setiap komponen ACBT dapat diubah, tetapi semua komponen siklus harus diterapkan dan bervariasi dengan kontrol respirasi. Teknik ini telah terbukti efektif dalam memobilisasi dan membersihkan kelebihan sekresi bronkial dan meningkatkan fungsi paru- 
paru (Maria W. Lamuvel, 2016; Derakhtanjani et al, 2019; Naseer et al, 2019). Studi kasus berbasis bukti ini bertujuan untuk mengetahui efektivitas ACBT dalam meningkatkan kemampuan fungsional paru terhadap pasien pasca operasi CABG dibandingkan dengan metode chest physiotherapy yang lain.

\section{METODE}

Tinjauan literatur dilakukan melalui pencarian artikel hasil publikasi ilmiah dilakukan secara online menggunakan metode PICO. Patient (P): Post ACBG; intervention (I): ACBT; comparison (C): intervensi fisioterapi lain; outcome (O): functional lung capacicity. Instrumen pencari yang digunakan adalah Pubmed dan Google scholar. Kata Kunci yang digunakan adalah Coronary Artery Bypass Graft (CABG) dan Active Cycle of Breathing Technique (ACBT), dengan menggunakan batasan (limit): studi yang dilakukan pada manusia, publikasi Bahasa inggris, kata kunci terdapat pada judul atau abstrak, tahun terbit mulai dari 2015 hingga sekarang, serta jenis publikasi berupa uji klinis, uji klinis randomisasi, meta-analisis, dan review.

Dengan metode pencarian yang telah dijelaskan di atas, didapatkan 73 artikel yang memenuhi kriteria. Penelusuran lebih lanjut dilakukan secara manual pada daftar pustaka yang relevan. Setelah penelusuran judul dan abstrak artikel-artikel tersebut, didapatkan 7 artikel yang memenuhi kriteria inklusi. Kemudian tahap pencarian dilanjutkan dengan membaca keseluruhan artikel dan ditemukan artikel yang sesuai sebanyak 1 artikel pada Pubmed dan 5 artikel pada Google scholar (Gambar 1).

\begin{tabular}{|c|c|c|}
\hline $\begin{array}{c}\text { Active Cycle of Breathing } \\
\text { Technique (ACBT) }\end{array}$ & AND & $\begin{array}{c}\text { Coronary Artery Bypass Graft } \\
\text { (CABG) }\end{array}$ \\
\hline \multicolumn{2}{|l|}{$\begin{array}{l}\text { Pubmed } \\
2\end{array}$} & $\begin{array}{c}\text { Google scholar } \\
71\end{array}$ \\
\hline \multicolumn{2}{|l|}{$\downarrow$} & $\downarrow$ \\
\hline \multicolumn{2}{|c|}{$\begin{array}{l}\text { Kriteria Inklusi : } \\
\text { - Artikel full teks } \\
\text { - } \text { Penanganan dengan latihan } \\
\text { - } \text { pernapasan } \\
\text { Tahun terbit diatas } 2015\end{array}$} & $\begin{array}{l}\text { Kriteria Eksklusi : } \\
\text { - Topik yang tidak sesuai } \\
\text { - } \\
\text { Artikel Non-data based }\end{array}$ \\
\hline \multicolumn{2}{|l|}{1} & $\downarrow$ \\
\hline \multicolumn{3}{|c|}{ Screening Judul/abstrak } \\
\hline \multicolumn{2}{|l|}{$\begin{array}{c}\text { Pubmed } \\
1 \\
\end{array}$} & $\begin{array}{c}\text { Google scholar } \\
6 \\
\end{array}$ \\
\hline & $\downarrow$ \\
\hline \multicolumn{3}{|c|}{ Membaca artikel full teks } \\
\hline $\begin{array}{c}\text { Pubmed } \\
1 \\
\end{array}$ & & $\begin{array}{c}\text { Google scholar } \\
5 \\
\end{array}$ \\
\hline
\end{tabular}

Gambar 1. Tahapan pencarian dan pemilihan artikel yang sesuai

\section{HASIL}

\section{Kasus}

Seorang pasien laki-laki berusia 42 tahun, pendidikan terakhir tamatan SMA datang dengan diagnosa medik hipertensi, dan chornic heart failer FC II akan dilakukan tindakan operasi CABG. Menjalani program fisioterapi pada satu hari setelah tindakan operasi. Dari 
hasil pemeriksaan fisioterapi ditemukan bahwa pasien dalam keadaan tertidur di bed, kesadaran kompos mentis, dan dapat berkomunikasi dengan baik. Dalam kondisi tersebut terpasang nasal kanul 1 liter, terpasang WSD, dan terpasang sringe pump, dan terpasang infus. Saat ini pasien mampu transfer dari duduk ke posisi duduk $45^{\circ}$ dengan bantuan 1 orang, ambulasi belum bisa dilakukan. Gerak nafas thoracoabdominal, dada simetri pada bagian upper, middle, dan lower. Namun, ditemukan penurunan ekspansi dada pada bagian middle dan lower. Terdapat nyeri gerak pada regio shoulder di semua gerakan. Ditemukan adanya retensi sputum pada segmen anterior apical lower lobus dexttra. Pemeriksaan six minute walking test menunjukan hasil 167,6 meter.

\section{Masalah Klinis}

Terdapat berbagai masalah klinis yang timbul akibat CABG. Fisioterapi menjadi salah satu upaya untuk menghilangkan masalah tersebut. Pemilihan latihan yang tepat dapat membantu menurunkan keluhan yang dialami pasien. Berdasarkan hal tersebut, diajukan pertanyaan klinis sebagai berikut: "Apakah pemberian Active Cycle of Breathing Technique (ACBT) dapat meningkatkan kemampuan fungsional paru pada pasien post CABG?’Untuk menjawab masalah klinis dari kasus diatas, maka dilakukan penelusuran litaeratur ilmiah, dengan hasil sebagai berikut:

Studi yang dilakukan oleh (Muthukumar, 2018) pada 15 pasien CABG menunjukkan bahwa ACBT dapat meningkatkan kemampuan fungsional paru di hari kelima sampai kesembilan post CABG. Metode evaluasi yang digunakan meliputi 6-Minute Walk Test (6MWT) untuk_menilai skala sesak, Visual Analog Scale (VAS) untuk skala nyeri pre dan post $\mathrm{CABG}$, serta pemeriksaan ekspansi thoraks. Pada hasil VAS menunjukkan penurunan nyeri, pasien pre-operatif dengan hasil VAS rerata 8.3, dan post CABG dengan ACBT hasil VAS rerata 1,6. Pasien pre-operatif dengan hasil Skala Borg rerata 5.4, sedangkan post CABG dengan ACBT Skala Borg rerata 1.4. ACBT memiliki efek dalam meningkatkan kedalaman pernapasan, kekuatan otot dan oksigenasi, di mana ketiga hal tersebut merupakan bagian dari mekanisme yang digunakan untuk mengurangi dispnea dan meningkatkan kualitas hidup. Hasil pemeriksaan ekspansi thoraks, pasien pre-operatif menunjukkan hasil rerata $2.1 \mathrm{~cm}$, dan post CABG dengan ACBT hasil rerata $2,7 \mathrm{~cm}$.

Hasil Studi perbandingan yang dilakukan oleh Ahmad S. et al (Derakhtanjani et al., 2019), juga menunjukkan bahwa intervensi ACBT dan fisioterapi dada rutin (routine chest physiotherapy) mempunyai efek yang sama terhadap penurunan nyeri, hal ini dibuktikan dengan nilai p-value sebesar 0.001 yang berarti ACBT dan routine chest physiotherapy menunjukkan efek signifikan terhadap penurunan nyeri pada pasien post CABG.

Hasil Studi perbandingan lain yang dilakukan (Jain and Mistry, 2017) pada 30 pasien CABG menunjukkan bahwa ACBT dan Incentive Spirometry (IS) mempunyai efek terhadap perubahan Respiratory Rate (RR) dan Breath-Holding Time (BHT). Hal ini ditunjukkan dengan nilai $p$-value terhadap perubahan RR sebesar 0.001, dan perubahan BHT sebesar 0.000 yang berarti intervensi ACBT dan IS memiliki efek yang siginifikan terhadap perubahan RR dan BHT pada pasien post CABG. Studi lain yang dikutip dari Maria W. et. al(Maria W. Lamuvel, 2016) pada 60 pasien CABG (usia 41-75 tahun) yang dikelompokkan dalam dua jenis intervensi. Kelompok satu berisi 30 pasien CABG dengan intervensi ACBT, dan kelompok dua berisi 30 pasien $\mathrm{CABG}$ dengan intervensi IS dan mobilisasi. Hasil menunjukkan bahwa ACBT dapat memperbaiki oksigenasi pada arteri di hari pertama post CABG. 


\section{PEMBAHASAN}

Perubahan fungsi paru yang diakibatkan oleh tindakan operasi gangguan kardiovaskuler telah terdokumentasi dari beberapa hasil studi. Perubahan fungsi paru ini dapat berdampak buruk pada kondisi pasien setelah operasi. Tindakan fisioterapi dada sangat perlu diterapkan pada kondisi ini, salah satu metode terapi yang dapat digunakan adalah Active Cycle of Breathing Technique (ACBT) merupakan teknik pernafasan aktif bertujuan untuk membantu batuk efektif, mengeluarkan retensi sputum, meningkatkan ekspansi thoraks, serta memperbaiki ventilasi paru ( $\mathrm{R}$ and Muthukumar, 2018). Pemberian intervensi ACBT pada pasien $\mathrm{CABG}$ dilakukan dengan posisi pasien duduk, punggung lurus sepenuhnya dengan bantuan sandaran. Selanjutnya, pasien diminta untuk melakukan ekspirasi panjang secara perlahan, tidak dipaksa, dilakukan sebanyak 5 sampai 7 kali untuk mendapatkan breathing control. Setelah itu, pasien diminta menghirup udara dalam (deep breathing) dengan mulut tertutup, dan menahan nafas dalam 3 sampai 4 detik, disebut tahap thoracic expansion. Tahap selanjutnya adalah pasien diminta untuk melakukan huffing sebanyak 2 sampai 3 kali dan coughing 2 sampai 3 kali. Saat melakukan coughing, pasien meletakkan salah satu tangannya di lokasi sayatan. Siklus ini diulangi minimal dua kali dan maksimal tiga kali dalam satu kali sesi terapi (Jain and Mistry, 2017). ACBT dapat diberikan sebagai intervensi pada hari pertama post CABG ketika di Intensive Care Unit (ICU), selanjutnya ACBT juga diberikan pada pasien $\mathrm{CABG}$ yang sudah masuk ruang rawat inap untuk pembersihan jalan nafas (Çirak et al., 2015).

ACBT dapat meningkatkan nilai oksigenasi arterial dan nilai dari $\mathrm{PaCO}_{2}$ secara signifikan dalam satu sesi latihan, hal ini membuktikan bahwa latihan ini dapat memberikan efek langsung pada ventilasi alveolar. Perbaikan ventilasi dapat dilihat menurunnya nilai respiratory rate (RR) dan skala borg. Teknik pernapasan dalam (deep breathing) yang dilakukan selama satu siklus ACBT dapat menstimulasi aliran udara diantara sekresi paru, sehingga dapat memudahkan dalam memobilisasi sekret dan dapat memperbaiki ventilasi. Perbaikan ini juga dapat dilihat dari peningkatan nilai FEV1 dan VC sebesar 34-72\%. ACBT akan menghasilkan peningkatan tekanan transpulmoner sehingga menyebabkan berkembangnya paru-paru serta unit-unit paru yang mengalami kolaps. Peningkatan tekanan transpulmoner tersebut akan memberikan ruang secara paksa pada alveoli yang berdekatan (Maria W. Lamuvel, 2016).

Dalam satu siklus ACBT juga terdapat latihan untuk meningkatkan ekspansi thoraks (thoracic expansion) ketika menahan nafas, fase ini akan berdampak terhadap peningkatan aliran udara ke area yang terjadi obstruksi, dan perbaikan ventilasi udara Peningkatan ekspansi thoraks pada breathing exercise dihubungkan dengan penurunan unit-unit paru yang kolaps sehingga ACBT dapat meningkatkan ekspansi thoraks, dan mencegah kolaps pada unit paru (Jain and Mistry, 2017). Selain itu, fase ekspirasi paksa atau huffing pada ACBT berupa kompresi dinamis dan kolapsnya saluran udara menuju mulut dari titik tekanan yang sama. Fase ini dapat membantu mengeluarkan retensi sputum dan menstimulasi refleks batuk. Hilangnya retensi sputum juga dihubungkan dengan perbaikan oksigenasi sehingga dapat mengurangi proses atelektasis dan meningkatkan ventilasi udara yang lebih maksimal.

Dalam upaya untuk meningkatkan kemampuan fungsional paru, ACBT dapat dikombinasi dengan latihan mobilisasi dini. Efektifitas pemberian ACBT dalam upaya meningkatkan peningktan fungsi paru dapat di evaluasi dengan uji jalan 6 menit / 6 six minute walking test (6MWT). Jarak 6MWT diukur sebelum dan sesudah dilakukan tindakan operasi, dengan pemberian ACBT pada fase awal CABG memberikan hasil 83\% jarak 6MWT sebelum operasi dapat diraih (Manapunsopee et al, 2020). 


\section{SIMPULAN DAN SARAN}

Latihan Active Cycle of Breathing Technique (ACBT) terbukti dapat meningkatkan kemampuan fungsional paru pasien post $\mathrm{CABG}$ dengan mengurangi nyeri, sesak nafas, retensi sputum, meningkatkan ekspansi thoraks, dan ventilasi paru. Hal ini dibuktikan dengan metode evaluasi seperti 6-Min Walk Test, Visual Analog Scale (VAS), skala borg, pemeriksaan ekspansi thoraks, pemeriksaan respiratory rate dan breath holding time.

\section{DAFTAR PUSTAKA}

Çirak Y, Karahan Z, Yelvar GDY, Erden I, Demirkiliç U. 2015. Is physiotherapy effective on the occurrence of postoperative pulmonary complications in patients undergoing coronary artery bypass graft surgery? A randomized controlled trial. Turkish Journal of Thoracic and Cardiovascular Surgery, 23(4): 622-630. https://doi.org/10.5606/tgkdc.dergisi.2015.11704.

Derakhtanjani AS, Jaberi AA, Haydari S, Bonabi TN. 2019. Comparison the effect of active cyclic breathing technique and routine chest physiotherapy on pain and respiratory parameters after coronary artery graft surgery: A randomized clinical trial. Anesthesiology and Pain Medicine, 9(5). https://doi.org/10.5812/aapm.94654.

Jain K, Mistry K. 2017. Comparative study on effects of active cycle of breathing technique and manual chest physical therapy after uncomplicated coronary artery bypass grafting surgery. Journal of Mahatma Gandhi University of Medical Sciences and Technology, 2(2): 65-68. https://doi.org/10.5005/jp-journals-10057-0037.

Manapunsopee S, Thanakiatpinyo T, Wongkornrat W, Chuaychoo B, Thirapatarapong W. 2020. Effectiveness of Incentive Spirometry on Inspiratory Muscle Strength After Coronary Artery Bypass Graft Surgery. Heart Lung and Circulation. Elsevier B.V, 29(8): 1180-1186. https://doi.org/10.1016/j.hlc.2019.09.009.

Maria W. Lamuvel A. 2016. Effect of ACBT and TENS on pulmonary function and pain perception in abdominal surgeries: A randomized control trial. International Journal of Health Sciences and Research (IJHSR), 6(6): 211-217.

Naseer BA, Al-Shenqiti AM, Ali ARH, Aljeraisi T. 2019. Effect of cardiac surgery on respiratory muscle strength. Journal of Taibah University Medical Sciences. Elsevier Ltd, 14(4): 337-342. https://doi.org/10.1016/j.jtumed.2019.06.002.

R M, Muthukumar T. 2018. Efficacy of active cycle of breathing technique on functional improvement in post CABG patient. Research in Medical \& Engineering Sciences, 5(1): 392-395. https://doi.org/10.31031/rmes.2018.05.000602.

Stein R, Maia CP, Silveira AD, Chiappa GR, Myers J, Ribeiro JP. 2009. Inspiratory Muscle Strength as a Determinant of Functional Capacity Early After Coronary Artery Bypass Graft Surgery. Archives of Physical Medicine and Rehabilitation. Elsevier Inc., 90(10): 1685-1691. https://doi.org/10.1016/j.apmr.2009.05.010.

Themistocleous I, Stefanakis M, Douda HT. 2017. Coronary Heart Disease Part I: Pathophysiology and Risk Factors. Journal of Physical Activity, Nutrition and Rehabilitation, (April): 167-175.

Thomas H, Diamond J, Vieco A, Chaudhuri S, Shinnar E, Cromer S, Perel P, Mensah GA, Narula J, Johnson CO, Roth GA, Moran AE. 2018. Global Atlas of Cardiovascular Disease 2000-2016: The Path to Prevention and Control. Global Heart, 13(3): 143-163. https://doi.org/10.1016/j.gheart.2018.09.511. 